\title{
Knowledge, Attitudes, and Treatment Seeking Behavior about Malaria and Its Control among Patients Attending Fever Clinic in a Tertiary Care Hospital of Eastern India
}

\author{
Chandra Narayan Gupta ${ }^{1}$, Kausik Maji ${ }^{* 2}$, Shatavisa Mukherjee ${ }^{3}$, Sukalyan Saha Roy $^{4}$, Sukanta Sen ${ }^{5}$ \\ ${ }^{1,2}$ Associate Professor, Department of General Medicine, ICARE Institute of Medical Sciences and Research, Haldia, West Bengal \\ ${ }^{3}$ Technical Associate, Department of Clinical \& Experimental Pharmacology, School of Tropical Medicine, Kolkata, West Bengal \\ ${ }^{4}$ Senior Resident, Department of Clinical \& Experimental Pharmacology, School of Tropical Medicine, Kolkata, West Bengal \\ ${ }^{5}$ Professor, Department of Pharmacology, ICARE Institute of Medical Sciences and Research, Haldia, West Bengal
}

\begin{abstract}
Background: Malaria continues to be a serious public health problem in South-East Asia including India. We assessed knowledge, attitudes, recognition of signs and symptoms and treatment seeking behavior about malaria and its control in patients with fever attending fever clinic at tertiary care hospital, Kolkata, India. Material and Methods: A cross-sectional questionnaire based survey was done in patients attending fever clinic. A total of $(\mathrm{n}=68)$ patients with fever were interviewed using standardized questionnaire. Results: A total of 68 subjects were interviewed, including 19 (27.94\%) females and 49 (72.06\%) males. Mean age was $39.8 \pm 17.2$ years (18-78). About 5 (7.35\%) were illiterate. All of the study participants had heard of malaria. The most common response on the source of information regarding malaria was radio (32.35\%) followed by TV (29.41\%) and friends (26.47\%). About 52.94\% replied that malaria can be prevented. Approx $39.7 \%$ subjects informed that fever plus chills are the most clinical features of malaria, followed by (fever+ chills + bodyache) in $32.35 \%$ cases. The most common response on the source of information regarding malaria transmission by mosquito bite was in $92.65 \%$ cases. Knowledge about breeding places of mosquitoes was informed as dirty stagnant water by $47.06 \%$. Conclusions: Greater awareness about malaria and undertaking a broader range of preventive actions for malaria influence appropriate treatment-seeking behaviour. This study was conducted to understand issues, which can be an important step towards developing strategies, aimed at controlling malaria. The positive attitudes and practices in relation to personal protection and prevention measures against malaria require marked improvement.
\end{abstract}

Keywords: Malaria, Knowledge, Attitude, Treatment seeking, Eastern India

\section{Introduction}

Malaria is a major public health problem in India causing an enormous burden to health and economy. In 2016, an estimated 216 million cases of malaria occurred worldwide (95\% confidence interval [CI]: 196-263 million), compared with 237 million cases in 2010 (95\% CI: 218-278 million) and 211 million cases in 2015 (95\% CI: 192-257 million). Despite substantial reductions, between 2014 and 2016, substantial increases in case incidence occurred in the WHO Region of the Americas, and marginally in the WHO South-East Asia, Western Pacific and African regions. ${ }^{[1]}$ Malaria is a public health problem in several parts of the country. About $95 \%$ population in the country resides in malaria endemic areas and $80 \%$ of malaria reported in the country is confined to areas consisting $20 \%$ of population residing in tribal, hilly, difficult and inaccessible areas. ${ }^{[2]}$ In India, about 1.31 million malaria cases with 753 deaths were reported in the year 2011 out of which more than half cases were of Plasmodium falciparum. ${ }^{[3]}$; the actual number of cases may be much more than the number of confirmed cases reported by National Malaria Control Programmes. ${ }^{[4]}$
Jharkhand and Bihar are malarius endemic states and under the Enhanced Malaria Control Project (EMCP) funded by the World Bank from $1997^{[5]}$ and contributes about twelve percent of the total malaria cases.

Malaria is a unique disease and has roots deep within human communities. There have been a considerable number of reports about knowledge, attitudes, and practices relating to malaria and its control from different parts of South East Asia. These reports concluded that misconceptions concerning malaria still exist and that practices for the control of malaria have been unsatisfactory. Thus, an advanced knowledge of the community beliefs and practices with respect to the disease is required to obtain and maintain its participation in surveillance and control activities. ${ }^{[6]}$

Beliefs and practices of malaria are often related to culture which can influence the effectiveness of control strategies. ${ }^{[7]}$ Thus, local knowledge, attitudes and practices related to the disease are key to implementation of culturally appropriate, sustainable, and effective interventions. ${ }^{[8]}$ Community perception, beliefs, and attitude about malaria control, symptom identification, treatment, and prevention 
influence efforts to address malaria and are often overlooked in control efforts; ${ }^{[9]}$ and vary from country to country and among individual households. ${ }^{[10]}$ Failure to consider community's knowledge, attitude, and practice (KAP) about malaria may contribute to the inability of the program to achieve sustainable control. $^{[11,12]}$ The objective was to collect baseline information concerning knowledge, attitudes, and practices of people in the study area regarding malaria among patients attending fever clinic of a tertiary care teaching hospital, Kolkata.

\section{Materials \& Methods}

The study was conducted from May to October 2014 in patients attending a dedicated fever clinic in a tertiary care teaching hospital. The study was a hospital based cross-sectional study. A structured questionnaire was used for interview. The questionnaire was administered to 100 randomly selected fever patients and 68 subjects who completed the complete interview were considered for final analysis. The first part of the questionnaire included demographic characteristic, whereas the second part had questions on knowledge, attitude and practices of residents about malaria, symptoms of malaria, transmission, protection methods of malaria, malaria vectors, and mosquito breeding, resting places, refusal of DDT spray and regular use of ITNs for malaria control etc. The questionnaire was prepared in English language but translated and communicated in local languages when necessary. Full verbal explanation of the study was given to members of selected patients or accompanying person with the fever patients and consent was obtained before inclusion as participants. Privacy and confidentiality were maintained throughout the study. The data were entered into a Microsoft Excel - Worksheet and analyzed using Epi Info, version 3.5.3. Descriptive statistics were carried out to measure relative frequencies, percentages, averages, and relative frequencies of the variables. Ethical clearance to conduct this study was obtained.

\section{Results}

A total of 68 subjects were interviewed, including 19 (27.94\%) females and $49(72.06 \%)$ males (Table 1). Mean age was $39.8 \pm$ 17.2 years (18-78). About 5 (7.35\%) were illiterate. Majority of the participants $39.71 \%$ was $16-30$ yrs followed by $38.23 \%$ of 31 45 yrs. Majority of the subjects were from upper lower socioeconomic class $92.65 \%$ followed by lower middle $(4.41 \%)$ and lower $(2.94 \%)$. None of the participants attended the Government fever clinic belong to upper middle or upper class. Detailed socio-demographic characteristics are presented in Table 1.

Table 1: Socio- economic profile of study population

\begin{tabular}{lll}
\hline & \multicolumn{2}{c}{ Socio-Economic Background } \\
\hline Age in years & Frequency & Percentage \\
\hline$<15$ & 0 & 0 \\
\hline $16-30$ & 27 & 39.71 \\
\hline $31-45$ & 26 & 38.23 \\
\hline $46-60$ & 13 & 19.12 \\
$>60$ & 2 & 2.94 \\
\hline
\end{tabular}

Socio-economic scale (according to Kuppuswamy's socioeconomic scale 2012)

\begin{tabular}{llll} 
Class & Score & Frequency & Percentage \\
\hline Upper & $26-29$ & 0 & 0 \\
\hline Upper Middle & $16-25$ & 0 & 0 \\
\hline Lower Middle & $11-15$ & 3 & 4.41 \\
\hline Upper Lower & $5-10$ & 63 & 92.65 \\
\hline Lower & $<5$ & 2 & 2.94 \\
\hline
\end{tabular}

Table 2: Knowledge about malaria among study participants

\begin{tabular}{|c|c|c|}
\hline \multicolumn{3}{|c|}{ Have you heard about malaria before? } \\
\hline No & 0 & 0 \\
\hline Yes & 68 & 100 \\
\hline \multicolumn{3}{|l|}{ If yes, from where? } \\
\hline Friends & 18 & 26.47 \\
\hline TV & 20 & 29.41 \\
\hline Community Health Worker & 9 & 13.23 \\
\hline Family Members & 17 & 25 \\
\hline School & 0 & 0 \\
\hline Malaria Camp & 0 & 0 \\
\hline Posters/Pamphlets & 0 & 0 \\
\hline Religious Meeting & 1 & 1.47 \\
\hline Health Camp & 3 & 4.41 \\
\hline Newspapers & 11 & 16.18 \\
\hline Community Meetings & 2 & 2.94 \\
\hline Radio & 22 & 32.35 \\
\hline Health Facility & 9 & 13.23 \\
\hline Others & 0 & 0 \\
\hline Not Applicable & 6 & 8.82 \\
\hline \multicolumn{3}{|l|}{ Can malaria be prevented } \\
\hline Yes & 36 & 52.94 \\
\hline No & 2 & 2.94 \\
\hline Don’t Know & 30 & 44.12 \\
\hline \multicolumn{3}{|c|}{ Knowledge about symptoms of malaria } \\
\hline Fever+ Chills & 27 & 39.7 \\
\hline Fever+ Chills + Bodyache & 22 & 32.35 \\
\hline $\begin{array}{l}\text { Fever + Chills }+ \text { Bodyache } \\
\text { Headache }\end{array}$ & 16 & 23.53 \\
\hline All Above Symptoms + Vomiting & 2 & 2.94 \\
\hline No Comments & 1 & 1.47 \\
\hline \multicolumn{3}{|c|}{ Knowledge about malaria transmission } \\
\hline Mosquito Bite & 63 & 92.65 \\
\hline By Flies & 1 & 1.47 \\
\hline Contaminated Water & 2 & 2.94 \\
\hline Chill Climate & 1 & 1.47 \\
\hline Malnutrition & 1 & 1.47 \\
\hline Eating Raw Vegetable & 0 & 0 \\
\hline Any Other & 0 & 0 \\
\hline No Comments & 5 & 7.35 \\
\hline \multicolumn{3}{|c|}{ Knowledge about breeding places of mosquitoes } \\
\hline Dirty Stagnant Water & 32 & 47.06 \\
\hline Due To Poor Personal Hygiene & 6 & 8.82 \\
\hline Flower Pots & 0 & 0 \\
\hline Coolers & 0 & 0 \\
\hline Air & 0 & 0 \\
\hline No Idea & 31 & 45.59 \\
\hline No Comments & 2 & 2.94 \\
\hline \multicolumn{3}{|c|}{ Idea about what diseases are transmitted by mosquitos } \\
\hline Dengue & 0 & 0 \\
\hline Malaria & 31 & 45.59 \\
\hline Dengue+Malaria & 30 & 44.12 \\
\hline
\end{tabular}


International Journal of Innovative Research in Medical Science (IJIRMS)

Volume 03 Issue 08 August 2018, ISSN: 2455-8737, Imp. Factor - 4.102

Available online at $-\underline{w w w . i j i r m s . i n}$

\begin{tabular}{|c|c|c|}
\hline Diarrhoea & 0 & 0 \\
\hline Typhoid & 0 & 0 \\
\hline No Idea & 3 & 4.41 \\
\hline No Comments & 2 & 2.94 \\
\hline \multicolumn{3}{|c|}{ Knowledge about preventive measures of malaria } \\
\hline Mosquito Nets & 33 & 48.53 \\
\hline Use Of Fans & 5 & 7.35 \\
\hline All The Above + Proper Clothing & 7 & 10.29 \\
\hline $\begin{array}{l}\text { All The Above + Avoid Water } \\
\text { Collection }\end{array}$ & 8 & 11.76 \\
\hline $\begin{array}{l}\text { Check For Mosquito Breeders In } \\
\text { Coolers }\end{array}$ & 2 & 2.94 \\
\hline $\begin{array}{l}\text { Check For Mosquito Breeders In } \\
\text { Flower Pots }\end{array}$ & 0 & 0 \\
\hline $\begin{array}{l}\text { Last Two Options+ Check Tyres For } \\
\text { Mosquito Breeding }\end{array}$ & 0 & 0 \\
\hline No Comments & 20 & 29.41 \\
\hline \multicolumn{3}{|c|}{ Any knowledge about self protection from mosquito bites? } \\
\hline Mats & 9 & 13.23 \\
\hline Coils & 9 & 13.23 \\
\hline Bednets & 47 & 69.12 \\
\hline Fans & 13 & 19.12 \\
\hline Others (Fire/Smoke) & 2 & 2.94 \\
\hline No Comments & 12 & 17.65 \\
\hline
\end{tabular}

All of the study participants had heard of malaria [Table 2]. The response to questions on knowledge with multiple options drew multiple responses. However, the most common response on the source of information regarding malaria was radio $(32.35 \%)$ followed by TV $(29.41 \%)$ and friends $(26.47 \%)$. Very little information about malaria was originated from malaria camp, and religious meeting. About $52.94 \%$ replied that malaria can be prevented. Approx $39.7 \%$ subjects informed that fever plus chills are the most clinical features of malaria, followed by (fever+ chills + bodyache) in $32.35 \%$ cases. The most common response on the source of information regarding malaria transmission by mosquito bite was in $92.65 \%$ cases. Knowledge about breeding places of mosquitoes was informed as dirty stagnant water by $47.06 \%$. Knowledge about preventive measures of malaria by mosquito nets was in $48.53 \%$ cases. Knowledge about self protection from mosquito bites by bed net was reported $69.12 \%$ [Table 2]. Idea about what diseases are transmitted by mosquitos was reported by $45.59 \%$ participants. About $44.12 \%$ of the subjects reported that they are aware that dengue and malaria are mosquito borne diseases. By using mosquito nets alone $48.53 \%$ reported that malaria can be prevented. About $11.76 \%$ reported by avoiding water collection in addition malaria can be prevented. Only $2.94 \%$ stressed upon "check for mosquito breeders in coolers" to avoid malaria parasite growth [Table 2]. As reported by participants self protection from mosquito bites may be done by bednets, fan, coils, and mosquito mat by $69.12 \%, 19.12 \%, 13.23 \%$ and $13.23 \%$ respectively.

Table 3: Treatment seeking behavior among study participants

\begin{tabular}{ccc}
\hline \multicolumn{1}{c}{$\begin{array}{c}\text { Frequency } \\
\text { Duration of suffering from fever }\end{array}$} & Percentage \\
\hline 1 day & 6 & 8.82 \\
2 days & 15 & 22.06 \\
3 days & 24 & 35.29 \\
4 days/ more & 23 & 33.82 \\
\hline
\end{tabular}

Pattern of fever

$\begin{array}{ccc}\text { Fever Continuous } & 6 & 8.82 \\ \text { Fever Remittent } & 41 & 60.29 \\ \text { Fever Intermittent } & 19 & 27.94 \\ \text { Don't Know } & 2 & 2.94\end{array}$

\section{Present complaints}

$\begin{array}{ccc}\text { Fever } & 67 & 98.53 \\ \text { Chills } & 59 & 86.76 \\ \text { Yellow Eyes } & 1 & 1.47 \\ \text { Headache } & 59 & 86.76 \\ \text { Bodyache } & 56 & 82.35 \\ \text { Nausea } & 19 & 27.94\end{array}$

$\begin{array}{lll}\text { Vomiting } & 14 & 20.59\end{array}$

Anemia/Pale Looking $\quad 0 \quad 0$

Generalized Weakness $\quad 22 \quad 32.35$

Yellowish Urine $\quad 13 \quad 19.12$

Loss of Appetite $\quad 39 \quad 57.35$

Diarrhea $\quad 0 \quad 0$

Constipation $\quad 0 \quad 0$

Convulsion

Others $\quad 16 \quad 23.53$

First action taken in case of fever

Home Remedy $\quad 2 \quad 2.94$

Self Medication $\quad 6 \quad 8.82$

Went to a Doctor/ Hospital $\quad 37 \quad 54.41$

Went to a Chemist For $\quad 20 \quad 29.41$

Medication

Went to Quack $\quad 1 \quad 1.47$

No Response $\quad 1 \quad 1.47$

Delay in seeking treatment from medical care provider after the onset of fever

$\begin{array}{ccc}\text { Same Day } & 18 & 26.47 \\ \text { Next Day } & 33 & 48.53 \\ \text { Day After Next } & 5 & 7.35 \\ \text { More Than 2 Days } & 12 & 17.65 \\ \text { Later } & 0 & 0\end{array}$

Reason for not seeking treatment for this illness

Not Severe Enough $\quad 38 \quad 55.88$

$\begin{array}{lll}\text { Got Better } & 0 & 0\end{array}$

Home Remedy $\quad 2 \quad 2.94$

Tried Self Medication $\quad 10 \quad 14.7$

$\begin{array}{lll}\text { Not Enough Money } & 5 & 7.35\end{array}$

Too Far Away $\quad 0 \quad 0$

No Transport $\quad 0 \quad 0$

Family Would Not Let Me $\quad 2 \quad 2.94$

Others $17 \quad 25$

Most important reason for choosing this medical care provider/ Govt hospital

$\begin{array}{ccc}\text { Proximity } & 51 & 75 \\ \text { Good Reputation } & 52 & 76.47 \\ \text { Inexpensive } & 22 & 32.35\end{array}$

Good Personal Experience $\quad 10 \quad 14.7$

$\begin{array}{lll}\text { Qualified Staff } & 1 & 1.47\end{array}$

Freely Available Drugs $\quad 30 \quad 44.12$

Relative/Friend Works Here $\quad 4 \quad 5.88$

$\begin{array}{ccc}\text { Can Get Treatment on Credit } & 0 & 0 \\ \text { Others } & 0 & 0\end{array}$

Distance from the care provider

$\begin{array}{ccc}>10 \mathrm{~km} & 2 & 2.94 \\ 5-10 \mathrm{~km} & 7 & 10.29 \\ 1-4 \mathrm{~km} & 54 & 79.41 \\ <1 \mathrm{~km} & 5 & 7.35\end{array}$


International Journal of Innovative Research in Medical Science (IJIRMS)

Volume 03 Issue 08 August 2018, ISSN: 2455-8737, Imp. Factor - 4.102

Available online at $-\underline{w w w . i j i r m s . i n}$

\begin{tabular}{|ccc|}
\hline \multicolumn{2}{|c}{$\begin{array}{c}\text { Mode of transport to the care provider } \\
\text { Walk }\end{array}$} & \multicolumn{1}{c}{} \\
\hline Bicycle & 0 & 75 \\
Motorcycle & 3 & 0 \\
\hline Private Car & 0 & 4.41 \\
\hline Public Taxi/Bus & 13 & 0 \\
\hline Metro/ Train & 1 & 19.12 \\
Auto & 2 & 2.94 \\
Others & 1 & 1.47 \\
Whom did you consult at this facility & \\
Doctor & 66 & 97.06 \\
Nurse & 0 & 0 \\
\hline Pharmacist & 23 & 33.82 \\
\hline Lab Technician & 50 & 73.53 \\
Traditional Healer & 0 & 0 \\
Others & 0 & 0 \\
\hline
\end{tabular}

Duration of admission to the facility for fever

No. of Night Stay

$\begin{array}{ccc}3 & 7 & 10.29 \\ 2 & 0 & 0 \\ 1 & 0 & 0 \\ 0 & 61 & 81.71\end{array}$

Advise to have any diagnostic test

No advice, but test

0

No advice, but had test

Advised but declined

$\begin{array}{cc}1 & 1.47 \\ 0 & 0\end{array}$

Advised and had test 67

98.53

Test recommended

Rapid Diagnostic Test (RDT)

Microscopy

1

Both RDT and Microscopy

Any Other

Don't Know

$\begin{array}{ll}0 & 0 \\ 0 & 0\end{array}$

Test Result

\begin{tabular}{|ccc|}
\hline Positive & 68 & 100 \\
\hline Negative & 0 & 0 \\
Don't Know & 0 & 0 \\
Type of malaria infection & detected in test report \\
\hline P. Falciparum & 21 & 30.88 \\
P. Vivax & 47 & 69.12 \\
\hline P. Malariae & 0 & 0 \\
P. Ovale & 0 & 0 \\
\hline P. Knowlesi & 0 & 0 \\
\hline Mixed Infection & 0 & 0 \\
\hline Don't Know & 0 & 0 \\
Receipt of medicine or prescription from this facility \\
Received medicine & 68 & 100 \\
\hline Received prescription & 5 & 7.35 \\
No, did not receive & 0 & 0 \\
Medicine/Prescription & & \\
\hline Don't know & 0 & 0 \\
Treatment regimen followed & \\
\hline Artesunate (50mg) + Sulfadoxine & 13 & 19.12 \\
(500mg) + Pyrimethamine & & \\
(25mg) & & \\
\hline Sulfadoxine (500mg) + & 2 & \\
Pyrimethamine (25mg) & & \\
\hline Artesunate (50mg) + Sulfadoxine & 6 & \\
(500mg) + Pyrimethamine & & \\
(25mg) + Primaquine Phosphate & & \\
\hline
\end{tabular}
(15mg)
Chloroquine (250mg)
47
69.12

Proper explanation by HCP regarding when and how drug to be taken

\begin{tabular}{|ccc|}
\hline Yes & 65 & 95.59 \\
\hline No & 3 & 4.41 \\
\hline Advised by HCP for follow up & \\
\hline Yes & 36 & 52.94 \\
\hline No & 32 & 47.06 \\
\hline
\end{tabular}

Any malaria infection in recent past

$\begin{array}{lll}\text { Within } 1 \text { month } & 2 & 2.94\end{array}$

3 month $\quad 6 \quad 8.82$

6 month $\quad 3 \quad 4.41$

More than 1 year $\quad 29 \quad 42.65$

Don't know $28 \quad 41.18$

Any anti-malarial treatment in the recent past

Within 1 Month $\quad 2 \quad 2.94$

3 Month $\quad 5 \quad 7.35$

6 Month $\quad 3 \quad 4.41$

More Than 1 Year $\quad 28 \quad 41.18$

Don't Know $\quad 24 \quad 35.29$

In more than $35.29 \%$ of the subjects with fever seeking treatment outside the home by 3 days followed by $33.82 \%$ by 4 days or more. Pattern of fever was found to be mainly remittent $(60.29 \%)$, followed by intermittent (27.94\%) and continuous (8.82\%) [Table $3]$. Chief clinical presentations were mainly fever $(98.53 \%)$, chills $(86.76 \%)$, headache $(86.76 \%)$ and bodyache $(82.35 \%)$. Loss of appetite (57.35\%), nausea (27.94), vomiting (20.59\%), and generalized weakness $(32.35 \%)$ were less commonly reported problems in patients with fever. None of the participants had reported anemia or pale looking, diarrhea, constipation or convulsion ever experienced during current fever attack. Majority of the subjects $54.41 \%$ went to doctor whenever fever was troublesome, followed by $29.41 \%$ first went to local chemist for medication. Few cases they tried home remedy (2.94\%), went to quack $(1.47 \%)$ or tried self medication $8.82 \%$. Some respondents, however, indicated that they resort to other treatment choices outside the home, when the first action at home fails.

Delay in seeking treatment from medical care provider after the onset of fever was observed next day $(48.53 \%)$ followed by same day $(26.47 \%)$ and more than 2 days $(17.65 \%)$. Respondents had reported main reasons for not seeking treatment for fever are "not severe enough" (55.88\%), 'tried self medication' $14.7 \%$, and 'not enough money' $7.35 \%$. about $25 \%$ respondents did mentioned other reasons for delaying treatment. Respondents reported the most important reasons for choosing this medical care provider/ Govt hospital are 'good reputation' $76.47 \%$, 'proximity of health clinic' $75 \%$, 'freely available drugs' $44.12 \%$ and 'inexpensive' $32.35 \%$. On an average $1-4 \mathrm{~km}$ respondents had to travel for seeking treatment in $79.41 \%$. About $10.29 \%$ cases they had travelled almost 5-10 km for seeking low cost better treatment facilities. Majority of subjects travelled to fever clinic by walk and public bus. Approximately $97.06 \%$ cases participants had consulted doctor at fever clinic followed by lab technician $73.53 \%$ for blood reports and $33.82 \%$ cases with pharmacists. Majority of respondents $81.71 \%$ did not get admitted with fever. Only $10.29 \%$ cases subjects got admitted in the hospital with an average of 3 night stay. 


\section{International Journal of Innovative Research in Medical Science (IJIRMS) Volume 03 Issue 08 August 2018, ISSN: 2455-8737, Imp. Factor - 4.102 \\ Available online at - $\underline{w w w . i j i r m s . i n}$}

About $98.53 \%$ cases blood test was advised with the history of fever patients attending fever clinic. About $98.53 \%$ microscopy of peripheral smear for malaria parasite was advised and based on report outcome treatment was served. In all most all cases in the present series were positive for malaria parasite. P. vivax was much common among present fever cases $69.12 \%$ followed by $\mathrm{p}$. falciparum $30.88 \%$. All the respondents or subjects with fever were prescribed medicine free of charges from fever clinic. Chloroquine was prescribed among $69.12 \%$ followed by $19.12 \%$ cases [Artesunate $(50 \mathrm{mg})+$ Sulfadoxine $(500 \mathrm{mg})+$ Pyrimethamine (25mg)] combination therapy. Only a few cases $2.94 \%$ [Sulfadoxine $(500 \mathrm{mg})+$ Pyrimethamine $(25 \mathrm{mg})]$ were prescribed and dispensed. About $95.59 \%$ cases health care professionals properly explained how drugs to be taken.

About $52.94 \%$ cases advised for follow up. As reported by respondents' $42.65 \%$ cases respondents had similar fever attack more than $1 \mathrm{yr}$ back. Only $2.94 \%$ cases there was history of repeated fever. About $41.18 \%$ cases took antimalarial treatment by more than one year back. About $7.35 \%$ cases they had antimalarial treatment within 3 months, which showed some had history of repeated attack of malaria infection [Table 3].

\section{Discussion}

Community knowledge, attitudes and practices relating to causation, transmission, prevention and treatment are key factors influencing malaria prevention and control. Results from surveys on knowledge, attitudes, and practices are applicable to design or improve malaria control programs, and to identify indicators for a program's effectiveness. ${ }^{[8]}$ All of the study participants had heard of malaria which is same as RK Gupta et al (2016). ${ }^{[12]}$

Study by Singh R et al had shown that about 180 (90.0\%) of the respondents reported any bed nets as the most common known protective method against malaria, while $128(64.0 \%)$ respondent had knowledge of insecticide treated bed net (ITNs). Second most common known preventive measure was use of mosquito coils by 79 (37.8\%) respondent. The knowledge of ways to prevent mosquito breeding, by cleaning of house surroundings was reported by $97(48.5 \%)$ and draining of stagnant water by 58 $(29.0 \%)$. Knowledge of the role of mosquitoes in malaria transmission (11.8\%) and cause of malaria $(9.6 \%)$ was observed to be low among the study population. Comprehensive knowledge about malaria prevention measures was high $(90 \%)$, but not reflecting in their practice (16\%). They have good knowledge of mosquito behavior (breeding areas $(64.5 \%)$, resting places $(70 \%)$ and biting time $(81 \%)$ ). Seeking hospital care for a febrile child was a good practice $(68.5 \%)$ observed. Attitudes regarding the best antimalarial therapy was limited $(56.7 \%)$ to chloroquine. ${ }^{[13]}$

Study by Vijayakumar KN et al8 showed about $63 \%$ of the respondents mentioned mosquito bite as the cause for this disease and $65 \%$ considered malaria as a serious problem. Qualitative data showed that people from remote villages seek treatment from traditional healers, Disharis. About $64 \%$ of the respondents stated that avoiding mosquito bites could prevent malaria. Majority (99\%) of the people reported using personal protection measures to avoid mosquito bites.

In this study, the majority of respondents reported to have heard of the chloroquine therapy, artemether combination therapy for treatment of malaria. An encouraging finding of Singh R et al13 study revealed that only $8 \%$ of respondent mentioned traditional healer as a choice of treatment, which was consistent with previous study in Nigeria. ${ }^{[14]}$ We found that almost all participants seek treatment for malaria from healthcare facilities, with more than half seeking treatment within $24 \mathrm{~h}$ of presenting with symptoms. Regarding the adoption of personal precautionary measures by participants in Sami Khairy et al study, ${ }^{[15]}$ mosquito nets were the most commonly used protective equipment, followed by antimosquito sprays $(47.3 \%$ and $29.8 \%$, respectively). Greater awareness about malaria and undertaking a broader range of preventive actions for malaria influence appropriate treatmentseeking behavior. A study in Cambodia showed that early recognition of malaria symptoms is the first important step to treatment seeking ${ }^{[16]}$ Study by Thandar et al. ${ }^{[17]}$ revealed caregivers were aware of malaria symptoms, about $50 \%$ were unaware that children under five and pregnant mothers are especially vulnerable to malaria.

The findings clearly demonstrate that the majority of the respondents had adequate knowledge and desirable health seekingbehavior; still a sizable proportion had misconception of the cause of malaria. The correction of such misconceptions about the relationship between mosquito bite and malaria through health education messages is critical for the success of malaria prevention and control. ${ }^{[18]}$ Community Knowledge on malaria prevention and control options is important and the effort is related to either to environmental management, personal protection or vector control. Study by Zewdie Aderaw et $\mathrm{al}^{[19]}$ revealed that unconsciousness $(28.3 \%)$, seizure/convulsion $(24.4 \%)$ and vomiting (16\%) were most frequently mentioned signs and symptoms of server malaria. This finding was supported by a study done in Myanmar which reported unconsciousness and convulsion are most frequently mentioned signs and symptoms of malaria. ${ }^{[20]}$

Study by Singh RK et al revealed that the awareness of malaria and its symptoms and transmission was very high (100\%) among the population with higher economic group and was significantly different $(p<0.05)$ from the low economic group. Similarly the perception that malaria can be prevented and is transmitted by mosquitoes was much higher than those with lower economic group $(\mathrm{p}<0.05){ }^{[21]}$

\section{Conclusion}

Greater awareness about malaria and undertaking a broader range of preventive actions for malaria influence appropriate treatmentseeking behaviour. Local knowledge and practice related to malaria is important for the implementation of culturally appropriate, sustainable and effective interventions. The findings of this study indicate that urban communities in Kolkata, West Bengal have high knowledge on malaria transmission, symptoms, and preventive measures. However, low education was detected as a major drawback for effective control, and intervention measures and information campaigns should focus on this high risk group. Increasing the knowledge about malaria transmission and benefits of using available effective preventive and control measures by the individual households and the community could contribute much to the overall reduction of the malaria burden. The obvious gap between the knowledge and practice related to malaria prevention requires innovative strategies based on local evidence that well suits the local circumstances to promote and encourage the 


\section{International Journal of Innovative Research in Medical Science (IJIRMS) \\ Volume 03 Issue 08 August 2018, ISSN: 2455-8737, Imp. Factor - 4.102 \\ Available online at - $\underline{w w w . i j i r m s . i n}$}

adoption and practice of personal protective measures. Most of the respondents had an acceptable level of knowledge and awareness about malaria, and indicated that they would seek treatment quickly if they developed symptoms.

\section{References}

[1] World malaria report 2017 http://www.who.int/malaria/publications/world-malariareport-2017/en/. [Accessed on 23rd March 2018]

[2] Malaria. http://nvbdcp.gov.in/index4.php?lang=1\&level=0\&linkid $=420 \&$ lid $=3699$. [Accessed on 23rd March 2018]

[3] National Vector Borne Disease Control Programme. Ministry of Health \& Family Welfare, Govt. of India. Available at: website https://india.gov.in/sectors/healthfamily/vectorborne.

[4] National Vector Borne Disease Control Programme. Ministry of Health \& Family Welfare, Govt. of India. Available at: website https://india.gov.in/sectors/healthfamily/vectorborne.

[5] Dhingra N, Joshi RD, Dhillon GP, Lal S. Enhanced malaria control project for World Bank support under National Malaria Eradication Programme (NMEP). J Commun Dis 1997; 29: 201-208.

[6] Ruebush TK II, Zeissig R, Koplan JP, Klein RE, Godoy HA. Community participation in malaria surveillance and treatment III. An evaluation of modifications in the volunteer collaborator network of Guatemala. American Journal of Tropical Medicine and Hygiene 1992; 50(1):85-98.

[7] Adera TD. Beliefs and traditional treatment of malaria in Kishe settlement area, Southwest Ethiopia. Ethiop Med J. 2003; 41:25-34.

[8] Vijayakumar KN, Gunasekaran K, Sahu SS, Jambulingam P. Knowledge, attitude and practice on malaria: A study in a tribal belt of Orissa State, India with reference to use of long lasting treated mosquito nets. Acta Trop. 2009; 112:137-42.

[9] Tyagi P, Roy A, Malhotra MS. Knowledge, awareness and practices towards malaria in communities of rural, semi-rural and bordering areas of East Delhi (India) $\mathrm{J}$ Vector Borne Dis. 2005;42:30-5.

[10] Deressa W, Ali A, Enquoselassie F. Knowledge, attitude and practice about Malaria the mosquito and antimalarial drugs in a rural community. Ethiop J Health Dev. 2003; 17:99-104.

[11] Rodríguez AD, Penilla RP, Henry-Rodríguez M, Hemingway J, Francisco Betanzos A, HernándezAvila JE. Knowledge and beliefs about malaria transmission and practices for vector control in Southern Mexico. Salud Publica Mex. 2003; 45:110-6.

[12] Gupta RK, Raina SK, Shora TN, Jan R, Sharma R, Hussain S. A household survey to assess community knowledge, attitude and practices on malaria in a rural population of Northern India. Journal of Family Medicine and Primary Care. 2016;5(1):101-107.

[13] Singh R, Musa J, Singh S, Ebere UV. Knowledge, attitude and practices on malaria among the rural communities in aliero, northern Nigeria. J Family Med Prim Care. 2014 Jan; 3(1):39-44.
[14] Jombo GT, Mbaawuaga EM, Denen AP, Alao OO, Peters EJ, Dauda MA, et al. Choices of drugs for selftreatment of malaria among adult women in a Nigerian city: Implications for the success of the ongoing 'roll back' malaria programme. J Microbiol Antimicrob. 2010; 2:57-63.

[15] Khairy S, Al-Surimi K, Ali A, Shubily HM, Al Walaan $\mathrm{N}$, Househ $\mathrm{M}$, et al. Knowledge, attitude and practice about malaria in south-western Saudi Arabia: A household-based cross-sectional survey. J Infect Public Health. 2017 Sep - Oct; 10(5):499-506.

[16] Lim S, Yasuoka J, Poudel KC, Ly P, Nguon C, Jimba M. Promoting community knowledge and action for malaria control in rural Cambodia: potential contributions of Village Malaria Workers. BMC Res Notes. 2012; 5:405.

[17] Thandar et al. Caregivers' treatment-seeking behaviour for children under age five in malaria-endemic areas of rural Myanmar: a cross-sectional study. Malaria Journal 2015 14:1.

[18] Laar et al. Community perception of malaria and its influence on health-seeking behaviour in rural Ghana: a descriptive study. MWJ 2013, 4:1.

[19] Aderaw Z, Gedefaw M (2013) Knowledge, Attitude and Practice of the Community towards Malaria Prevention and Control Options in AntiMalaria Association Intervention Zones of Amahara National Regional State, Ethiopia. J Trop Dis 1: 118.

[20] Kyawt-Kyawt-Swe, Pearson A. Knowledge, attitudes and practices with regard to malaria control in an endemic rural area of Myanmar. Southeast Asian J Trop Med Public Health 2004; 35: 53-62.

[21] Singh RK, Haq S, Dhiman RC (2013) Studies on Knowledge, Attitude and Practices in Malaria Endemic Tribal Areas of Bihar and Jharkhand, India. J Trop Dis 1: 110.

\section{Corresponding Author:}

\section{Dr Kausik Maji,}

Associate Professor, Department of General Medicine,

ICARE Institute of Medical Sciences and Research, Haldia, West Bengal 721645

$\mathrm{Ph}:+91-9434205642(\mathrm{M})$

Email: kausikm25 [at] gmail.com 